УДК 629.113

UDC 629.113

\author{
Сахно $^{1}$ В.П., Мурований² ${ }^{2}$.С., Поляков ${ }^{1}$ В.М., Місько ${ }^{1}$ С.М. \\ ${ }^{1}$ Національний транспортний університет \\ 2 Луцький національний технічний університет
}

\title{
ДО ПОРІВНЯЛЬНОЇ ОЦІНКИ ТРИЛАНКОВИХ ПАСАЖИРСЬКИХ ПОЇЗДІВ ЗА СТІЙКІСТЮ РУХУ
}

\begin{abstract}
Виконано порівняння триланкових метробусів різних компонувальних схем за показниками стійкості руху. Показано, що за величиною критичної швидкості руху перевагу слід віддати триланковому метробусу, виконаному за напівпричіпною схемою. Визначені шляхи підвищення критичної швидкості руху метробуса, виконаного за причіпною схемою. Встановлено, що на підвищення поперечної горизонтальної стійкості метробуса позитивно позначається зменшення тиску повітря в шинах передньої осі і збільшення в шинах задньої осі першого причепа (напівпричепа), зсув центра мас причіпних ланок до передньої осі, збільшення коефіцієнтів опору бічному відведенню шин коліс другої осі причепа (напівпричепа), збільшення маси автобуса і першого причепа тощо. Вплив інших параметрів або незначний, або зовсім відсутній.

Ключові слова: метробус, автобус, причіп, напівпричіп, рівняння руху, стійкість, швидкість, кути складання, управління.
\end{abstract}

\section{ВСТУП}

Безпечні системи громадського транспорту все більше розглядаються як важливий засіб безпечного підвищення мобільності населення, особливо в міських районах, які страждають від зростаючих транспортних заторів. У багатьох містах з високими доходами особливо акцентується політика скорочення використання особистого автомобільного транспорту за допомогою інвестицій в розвиток мереж громадського транспорту. Інвестиції в безпечний громадський транспорт розглядаються також як механізм, що стимулює зростання фізичної активності i, отже, сприяє зміцненню здоров'я населення

Метробус або нова система автобусного руху "Швидкісний автобусний транспорт" (Bus Rapid Transport, BRT) $\epsilon$ результатом розвитку мережі автобусного суспільного транспорту. В порівнянні 3 метро цей проект володіє явними перевагами: менша вартість створення мережі, менша вартість рухомого складу, мобільність та ін. [1].

Система BRT має ряд незаперечних переваг [2]

- висока пасажиромісткість і ефективні платіжні системи забезпечують недорогий проїзд;

- висока швидкість пересування дозволяє метробусу перевозити вагому частку пасажиропотоку, що сприяє зменшенню кількості автомобілів на дорогах міста i, відповідно, зменшенню викидів відпрацьованих газів;

- розширена інформаційна система інформує пасажирів про розклад маршрутів.

Зручність, безпека і покращувана організація дорожнього руху - це далеко не все, що зможе дати пасажирам система швидкісного автобусного транспорту. У цій системі пасажирські швидкісні автобуси пересуваються по спеціально виділених смугах. Вони відокремлені від проїжджої частини i обладнані закритими пасажирськими станціями 3 платформами на одному рівні $\mathrm{i}$ підземними переходами.

Отже, основними перевагами BRTсистем $€$ порівняно невелика вартість будівництва, швидкість будівництва лінії, невелика вартість автобусів, можливість гнучко змінювати пасажиропотік за рахунок інтенсивності руху, можливість частково використовувати лінію BRT для іншого спецтранспорту. Може використовувати як окремі полоси, так і частково рухатись по існуючих дорогах. При відокремлених полосах може розвивати велику швидкість у місті. Може мати різні маршрути на одній лінії, на відміну від метрополітену. Зменшує використання приватного автотранспорту, поліпшує транспорту ситуацію та дає можливість повністю відмовитись від невеликих маршрутних автобусів у містах [2]. Ці переваги проявляються, перш за все, при максимальному використанні пасажиромісткості метробусів, тобто при застосуванні триланкових метробусів, рис. 1. 


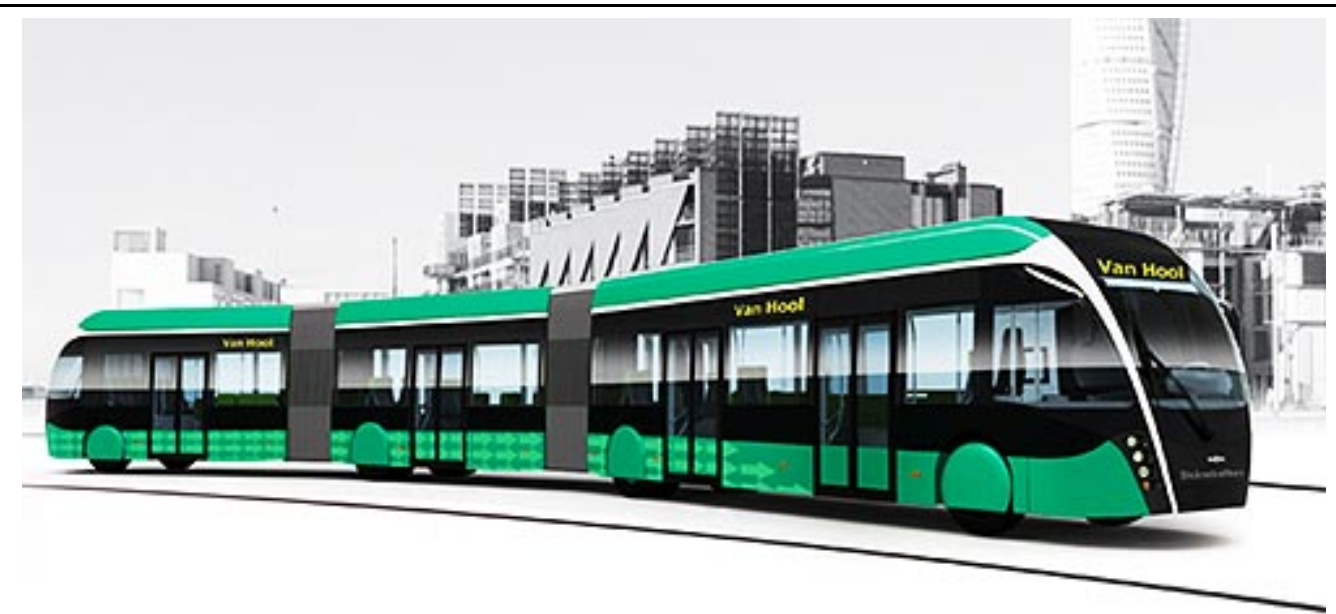

Рисунок 1 - Триланковий метробус

\section{АНАЛІЗ ЛІТЕРАТУРНИХ ДАНИХ ТА ПОСТАНОВКА ПРОБЛЕМИ}

При проектуванні метробусів, враховуючи можливість їх створення з різними причіпними модулями, проблематичним є прогнозування керованості і стійкості руху таких АТЗ.

Характеристики стійкості та керованості, як відомо, визначаються комбінацією експлуатаційних, масово-геометричних і конструктивних параметрів модулів АТЗ. У загальному випадку бажані сполучення вказаних параметрів з точки зору стійкості та керованості навіть для одного і того ж транспортного засобу в діапазоні експлуатаційних навантажень і швидкостей руху бувають різними. Як, наслідок, є складність отримання на ранніх стадіях створення АТЗ точних конструктивних параметрів і кількісних показників за критеріями стійкості та керованості руху [3].

При розгляді питань стійкості руху триланкових АТЗ вона розглядається для двох схем керування - розімкнутої і замкнутої. При розімкнутій схемі керування оцінюється потенційна стійкість руху самого АТЗ, при замкнутій - стійкість руху системи водій -АТЗ [3].

У відомих на-сьогодні роботах питання керованості і стійкості розглядаються в двох аспектах [3]:

1. Дослідження 3 урахуванням характеристик всіх елементів системи "водій-автомобільдорога", що розглядається як замкнена система автоматичного управління .

2. Дослідження власної стійкості і керованості автомобіля (автопоїзда), за якого вплив водія виключається.

У першій групі робіт частіше за все розглядається проблема загалом, тобто досліджується відразу і керованість і стійкість у цій складній системі отримання, переробки і передачі інформації, формування керуючих впливів, спрямованих на зменшення відхилень як автомобіля-тягача, так $\mathrm{i}$ причіпних ланок від бажаного процесу. При цьому поняттям керованості і стійкості додається значення, що застосовується в теорії автоматичного управління. При такому вивчені керованість розглядає ті або інші характеристики перехідних процесів при найпростіших типових керуючих впливах [3]. Стійкість характеризує поведінку системи у перехідному режимі і відноситься передусім до власних рухів системи, що породжуються початковими умовами (збуреннями) і внутрішніми іiі властивостями, але не зовнішніми впливами. Стійкість розглядається стосовно до будь-якого процесу, як керованому, так і некерованому [3].

У другій групі робіт автомобіль розглядається ізольовано як об'єкт регулювання, а стійкість руху системи водій - АТЗ визначається стійкістю автотранспортного засобу і психофізичними можливостями водія, а також рівнем і характером діючих збурень. Як показали виконані розрахунки для різних видів АТЗ, наявність замкнутої схеми керування дозволяє підвищити їхню критичну швидкість руху в 1,5-2 рази і збільшити число ланок, стійкість яких може бути забезпечена [3].

Таким чином, якщо забезпечується стійкість руху АТЗ, то стійкість руху системи водій - АТЗ також забезпечується, причому з великим запасом. Тому досить розглянути рух при керуванні за розімкнутою схемою, тобто потенційну стійкість самого АТЗ.

У сучасному автомобілебебудуванні при створені багатоланкових автопоїздів, у тому числі і пасажирських, питання вибору причіпних ланок є актуальним і воно активно обговорюється в літературі. Розрізняють дві основні схеми багатоланкових автопоїздів - причіпна і напівпричіпна. У причіпній схемі кожна ланка опирається на свої осі, у напівпричіпній - як на свої осі, так і на вісь

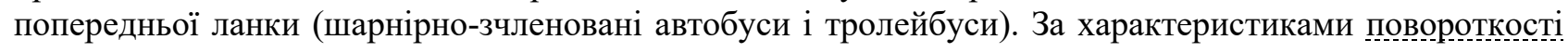


найбільш ефективною $є$ схема 3 усіма керованими колесами причіпних ланок. Вона може забезпечувати найменші радіуси повороту та найкраще маневрування в обмежених умовах руху. Однак така схема дуже складна у конструктивному виконанні і породжує безліч проблем, пов'язаних 3 проектуванням і експлуатацією таких транспортних засобів, серед характеристик яких виділяються складність руху заднім ходом, вписуваність у поворот і стійкість прямолінійного руху [4].

Теоретичні засади аналізу базуються на основі математичних моделей прямолінійного та керованого рухів автомобіля і автопоїзда, що розроблені для автомобілів, двох- та триланкових автопоїздів [5-8]. Проте їх застосування для триланкових метробусів є проблематичним у зв'язку 3 різними компонувальними схемами автопоїздів і метробусів, різними навантаженнями на окремі ланки, різними системами управління тощо. Звідси виникає проблема прогнозування маневреності i стійкості руху триланкових метробусів при їх русі як у загальному транспортному потоці, так і по спеціально виділеним смугам руху.

\section{ЦІЛЬ ТА ЗАДАЧІ ДОСЛІДЖЕННЯ}

Із аналізу літературних джерел і проблематики дослідження метою роботи $є$ покращання стійкості руху триланкових метробусів шляхом вибору раціональної компонувальної схеми та конструктивних параметрів його причіпних ланок.

Відповідно до мети задачі дослідження визначені в такий спосіб:

- розробити математичну модель неусталеного криволінійного руху триланкового метробуса i на їі основі провести розрахунково-теоретичні дослідження для визначення і порівняльної оцінки стійкості руху метробусів різних компонувальних схем за обраною системою оціночних показників;

- проаналізувати вплив конструктивних і експлуатаційних параметрів на стійкість руху метробусів різних компонувальних схем.

- розробити рекомендації щодо практичного використання результатів дослідження 3 метою підвищення показників стійкості руху триланкових метробусів різних компонувальних схем.

\section{РЕЗУЛЬТАТИ ДОСЛІДЖЕНЬ}

У роботі [5], в якій розглядалися питання маневреності триланкових метробусів причіпної і напівпричіпної компонувальних схем приймалася модульна побудова автопоїзда. За цієї умови метробус представлявся у вигляді трьох модулів - автобуса і двох причіпних ланок.

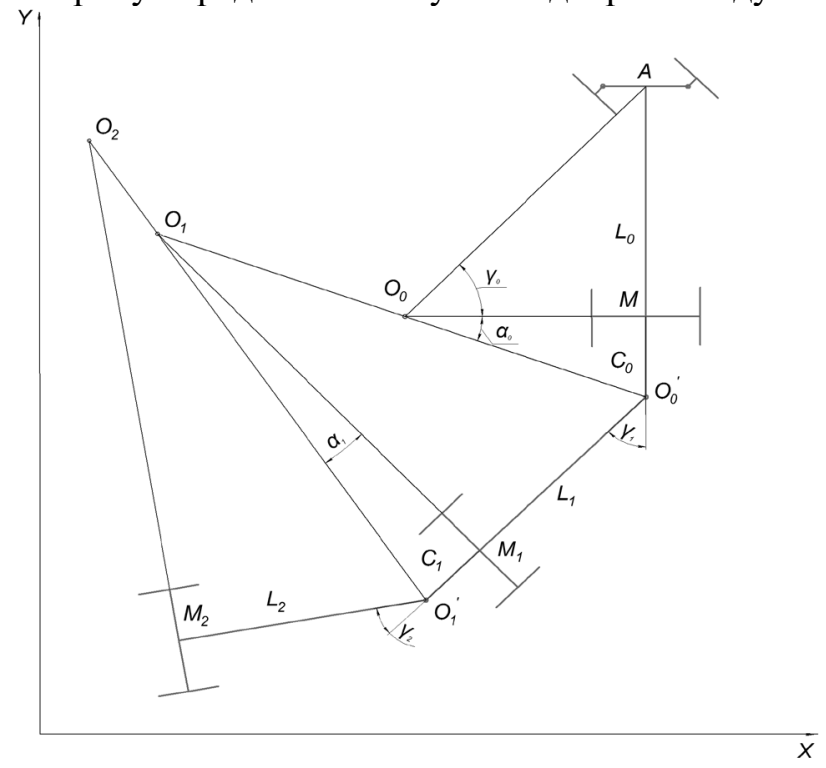

a)

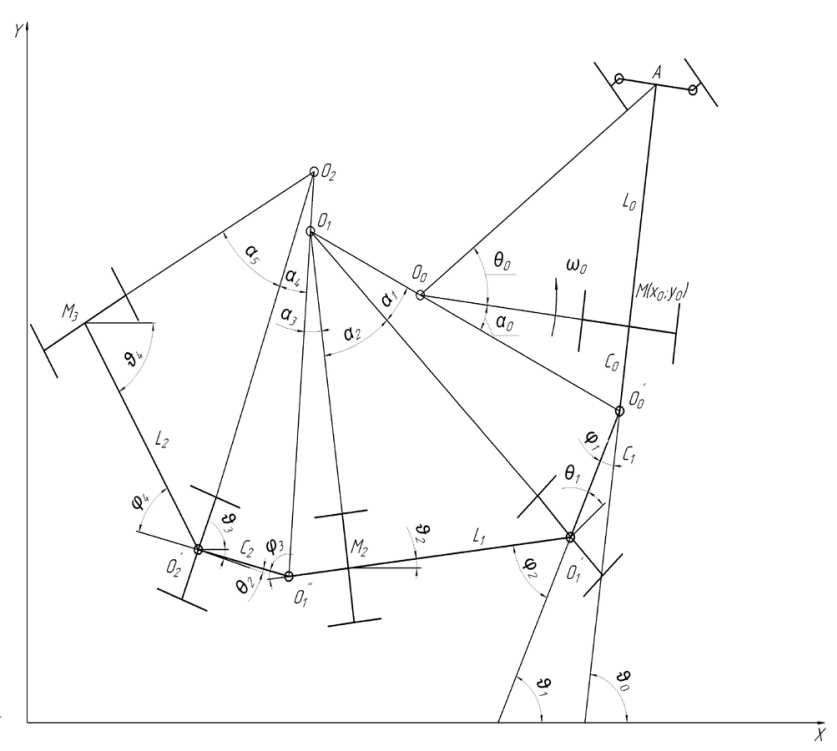

б)

Рисунок 3 - Розрахункова схема метробуса:

а) - за напівпричіпною схемою, б) - за причіпною схемою

За модульної побудови автопоїзда автобус представляється у вигляді одного модуля - кістяка 3 передніми керованими колесами, кути повороту яких $\theta_{1}$ i $\theta_{1}^{\prime}$, але для подальших розрахунків приймаємо $\theta_{1}^{\prime}=\theta_{1}=\theta_{1}$ і двома (однією) задніми неповоротними осями. Причіпні ланки також представлялися у вигляді або одного модуля - кістяка 3 неповоротними колесами (осями) за напівпричіпної компонувальної схеми, або із двох кінематично незалежних елементів - платформи 3 
неповоротною задньою віссю і поворотної осі з дишлем, причому між ними існує шарнірний зв’ язок, кути повороту яких $\theta_{11}$ i $\theta_{12}$.

Диференціальні рівняння руху триланкового метробуса, що складається із двовісного автобуса i двох причепів (більш загальний випадок) були отримані в роботі [5] і записані у вигляді:

$\left(m+m_{1}+m_{2}+m_{3}+m_{4}\right)(\dot{V}-U \omega)+c \omega^{2}\left(m_{1}+m_{2}+m_{3}+m_{4}\right)-\left[m_{1} d_{1}+m_{2} l_{1}+\right.$

$+\left(m_{3}+m_{4}\right) l_{2}\left[\left(\dot{\omega}-\ddot{\varphi}_{1}\right) \sin \varphi_{1}-\left(\omega-\dot{\varphi}_{1}\right)^{2} \cos \varphi_{1}\right]-m_{2} d_{2}\left[\left(\dot{\omega}-\ddot{\varphi}_{1}-\ddot{\varphi}_{2}\right) \sin \left(\varphi_{1}+\varphi_{2}\right)-\right.$

$\left.-\left(\dot{\omega}-\dot{\varphi}_{1}-\dot{\varphi}_{2}\right)^{2} \cos \left(\varphi_{1}+\varphi_{2}\right)\right]-\left(m_{3} d_{4}+m_{4} l_{3}\right)\left[\left(\dot{\omega}-\ddot{\varphi}_{1}-\ddot{\varphi}_{2}\right) \sin \left(\varphi_{1}+\varphi_{2}\right)-\right.$

$\left.-\left(\dot{\omega}-\dot{\varphi}_{1}-\dot{\varphi}_{2}\right)^{2} \cos \left(\varphi_{1}+\varphi_{2}\right)\right]-m_{4} d_{4}\left[\left(\dot{\omega}-\ddot{\varphi}_{1}-\ddot{\varphi}_{3}-\ddot{\varphi}_{4}\right) \sin \left(\varphi_{1}+\varphi_{3}+\varphi_{4}\right)-\right.$

$\left.-\left(\dot{\omega}-\dot{\varphi}_{1}-\dot{\varphi}_{3}-\dot{\varphi}_{4}\right)^{2} \cos \left(\varphi_{1}+\varphi_{3}+\varphi_{4}\right)\right]=$

$=-\left(X_{1} \cos \theta_{1}+Y_{1} \sin \theta_{1}\right)+X_{12}-X_{31} \times \cos \left(\theta_{11}+\varphi_{1}+\varphi_{2}\right)-X_{32}-Y_{31} \times \sin \left(\theta_{11}+\varphi_{1}+\varphi_{2}\right)-$

$-Y_{32}-X_{41} \times \cos \left(\theta_{12}+\varphi_{1}+\varphi_{2}\right)-X_{42}-Y_{41} \times \sin \left(\theta_{12}+\varphi_{1}+\varphi_{2}\right)-Y_{42}$;

для поперечної швидкості центра мас

$\left(m+m_{1}+m_{2}+m_{3}+m_{4}\right)(\dot{U}-V \omega)-c \omega^{2}\left(m_{1}+m_{2}+m_{3}+m_{4}\right)-\left[m_{1} d_{1}+m_{2} l_{1}+\right.$

$+\left(m_{3}+m_{4}\right) l_{2}\left[\left(\dot{\omega}-\ddot{\varphi}_{1}\right) \cos \varphi_{1}+\left(\omega-\dot{\varphi}_{1}\right)^{2} \sin \varphi_{1}\right]-m_{2} d_{2}\left[\left(\dot{\omega}-\ddot{\varphi}_{1}-\ddot{\varphi}_{2}\right) \cos \left(\varphi_{1}+\varphi_{2}\right)+\right.$

$\left.-\left(\dot{\omega}-\dot{\varphi}_{1}-\dot{\varphi}_{2}\right)^{2} \sin \left(\varphi_{1}+\varphi_{2}\right)\right]-\left(m_{3} d_{3}+m_{4} l_{3}\right)\left[\left(\dot{\omega}-\ddot{\varphi}_{1}-\ddot{\varphi}_{3}\right) \cos \left(\varphi_{1}+\varphi_{3}\right)+\right.$

$\left.+\left(\dot{\omega}-\dot{\varphi}_{1}-\dot{\varphi}_{3}\right)^{2} \sin \left(\varphi_{1}+\varphi_{3}\right)\right]-m_{4} d_{4}\left[\left(\dot{\omega}-\ddot{\varphi}_{1}-\ddot{\varphi}_{3}-\ddot{\varphi}_{4}\right) \cos \left(\varphi_{1}+\varphi_{3}+\varphi_{4}\right)+\right.$

$\left.+\left(\dot{\omega}-\dot{\varphi}_{1}-\dot{\varphi}_{3}-\dot{\varphi}_{4}\right)^{2} \sin \left(\varphi_{1}+\varphi_{3}+\varphi_{4}\right)\right]=$

$=-\left(X_{1} \sin \theta-Y_{1} \cos \theta\right)+Y_{12}-X_{31} \times \sin \left(\theta_{11}+\varphi_{1}+\varphi_{2}\right)+Y_{31} \times \cos \left(\theta_{11}+\varphi_{1}+\varphi_{2}\right)+Y_{32}+$

$+X_{41} \times \sin \left(\theta_{12}+\varphi_{1}+\varphi_{3}+\varphi_{4}\right)+Y_{41} \times \cos \left(\theta_{12}+\varphi_{1}+\varphi_{3}+\varphi_{4}\right)+Y_{42}$

- для кутової швидкості тягача

$I \omega+[\dot{\omega} c-(U+V \omega)] c\left(m_{1}+m_{2}+m_{3}+m_{4}\right)+c\left\{\left[m_{1} d_{1}+m_{2} l_{1}+\left(m_{3}+m_{4}\right) l_{2}\right] \times\right.$

$\times\left[\left(\dot{\omega}-\ddot{\varphi}_{1}\right) \cos \varphi_{1}+\left(\omega-\dot{\varphi}_{1}\right)^{2} \sin \varphi_{1}\right]+m_{2} d_{2}\left[\left(\dot{\omega}-\ddot{\varphi}_{1}-\ddot{\varphi}_{2}\right) \cos \left(\varphi_{1}+\varphi_{2}\right)+\left(\omega-\dot{\varphi}_{1}-\dot{\varphi}_{2}\right)^{2} \times\right.$

$\left.\times \sin \left(\varphi_{1}+\varphi_{2}\right)\right]+\left(m_{3} d_{4}+m_{4} l_{3}\right)\left[\left(\dot{\omega}-\ddot{\varphi}_{1}-\ddot{\varphi}_{2}\right) \cos \left(\varphi_{1}+\varphi_{2}\right)+\left(\omega-\dot{\varphi}_{1}-\dot{\varphi}_{2}\right)^{2} \times \sin \left(\varphi_{1}+\varphi_{3}\right)\right]+$

$\left.+m_{4} d_{4}\left[\left(\dot{\omega}-\ddot{\varphi}_{1}-\ddot{\varphi}_{3}-\ddot{\varphi}_{4}\right) \cos \left(\varphi_{1}+\varphi_{3}+\varphi_{4}\right)+\left(\omega-\dot{\varphi}_{1}-\dot{\varphi}_{3}-\dot{\varphi}_{4}\right)^{2} \sin \left(\varphi_{1}+\varphi_{3}+\varphi_{4}\right)\right]\right\}=$

$=H\left(X_{1} \cos \theta_{1}+Y_{1} \sin \theta_{1}\right)+\varepsilon X_{1}+a\left(Y_{1} \cos \theta-X_{1} \sin \theta\right)+X_{12} H_{1}-Y_{12} b_{11}-c\left[X_{31} \times \sin \left(\theta_{11}+\varphi_{1}+\varphi_{2}\right)+\right.$

$\left.+Y_{31} \times \cos \left(\theta_{11}+\varphi_{1}+\varphi_{2}\right)+Y_{32}\right]+c\left[X_{41} \times \sin \left(\theta_{12}+\varphi_{1}+\varphi_{2}\right)+Y_{41} \times \cos \left(\theta_{12}+\varphi_{1}+\varphi_{2}\right)+Y_{42}\right]$

- для кістяка першого причепа

$\left[I_{1}+m_{1} d_{1}^{2}+m_{2} l_{1}^{2}+\left(m_{3}+m_{4}\right) l_{2}^{2}\right] \times\left(\dot{\omega}-\ddot{\varphi}_{1}\right)+\left[m_{1} d_{1}+m_{2} l_{1}+\left(m_{3}+m_{4}\right) l_{2} \times\left[\left(\dot{V}-U \omega+c \omega^{2}\right) \times\right.\right.$

$\left.\times \sin \varphi_{1}+\left(V \omega-\dot{U}-c \omega^{2}\right) \times \cos \varphi_{1}\right]-m_{2} d_{2} l_{1}\left[\left(\dot{\omega}-\ddot{\varphi}_{1}-\ddot{\varphi}_{2}\right) \cos \varphi_{2}+\left(\omega-\dot{\varphi}_{1}-\dot{\varphi}_{2}\right)^{2} \sin \varphi_{2}\right]-$

$-l_{2}\left\{\left(m_{3} d_{3}+m_{4} l_{3}\right)\left[\left(\omega-\dot{\varphi}_{1}-\dot{\varphi}_{3}\right)^{2} \cos \varphi_{3}+\left(\omega-\dot{\varphi}_{1}-\dot{\varphi}_{3}\right)^{2} \sin \varphi_{3}\right]+m_{4} d_{4}\left[\left(\dot{\omega}-\ddot{\varphi}_{1}-\ddot{\varphi}_{3}-\ddot{\varphi}_{4}\right) \times\right.\right.$

$\left.\left.\times \cos \left(\varphi_{3}+\varphi_{4}\right)+\left(\dot{\omega}-\ddot{\varphi}_{1}-\ddot{\varphi}_{3}-\ddot{\varphi}_{4}\right) \times \sin \left(\varphi_{3}+\varphi_{4}\right)\right]\right\}=$

$=l_{1}\left[X_{31} \times \sin \left(\theta_{11}+\varphi_{2}\right)+Y_{31} \times \cos \left(\theta_{11}+\varphi_{2}\right)+l_{2}\left[X_{41} \times \sin \left(\theta_{12}+\varphi_{3}+\varphi_{4}\right)+\right.\right.$

$+Y_{41} \times \cos \left(\theta_{12}+\varphi_{3}+\varphi_{4}\right)+M_{1}-M_{2}+M_{3}$

- для керованої осі першого причепа 


$$
\begin{aligned}
& {\left[\left(I_{2}+m_{2} d_{2}^{2}\right] \times\left(\ddot{\varphi}_{3}-\dot{\omega}+\ddot{\varphi}_{1}\right)\right]+\left(m_{3} d_{3}+m_{4} l_{3} \times\left(\left[\left(\dot{V}-U \omega+c \omega^{2}\right) \times \sin \left(\varphi_{1}+\varphi_{3}\right)+\right.\right.\right.} \\
& \left.\left.+\left(V \omega-\dot{U}-c \omega^{2}\right) \times \times \cos \left(\varphi_{1}+\varphi_{3}\right)\right]+l_{2}\left[-\left(\dot{\omega}-\ddot{\varphi}_{1}\right) \times \cos \varphi_{3}+\left(\dot{\omega}-\ddot{\varphi}_{1}\right) \times \sin \varphi_{3}\right]\right\}+ \\
& +l_{3} m_{4} d_{4} \times\left[-\left(\dot{\omega}-\ddot{\varphi}_{1}-\ddot{\varphi}_{3}-\ddot{\varphi}_{4}\right) \times \cos \varphi_{4}-\left(\omega-\dot{\varphi}_{1}-\dot{\varphi}_{3}-\dot{\varphi}_{4}\right)^{2} \times \sin \varphi_{4}\right]= \\
& l_{3}\left[X_{31} \times \sin \left(\theta_{12}+\varphi_{3}\right)+X_{32} \sin \varphi_{3}+Y_{31} \times \cos \left(\theta_{12}+\varphi_{3}\right)+Y_{32} \cos \varphi_{3}+M_{3}-M_{4} ;\right.
\end{aligned}
$$

\section{- для кістяка другого причепа}

$$
\begin{aligned}
& {\left[I_{3}+m_{3} d_{3}^{2}+m_{4} l_{3}^{2}\right] \times\left(\ddot{\varphi}_{3}-\dot{\omega}-\ddot{\varphi}_{1}\right)+\left(m_{3} d_{3}+m_{4} l_{3}\right) \times\left[\left(\dot{U}-V \omega+c \omega^{2}\right) \times \sin \left(\varphi_{1}+\varphi_{3}\right)+\right.} \\
& \left.\left.\left.+(V \omega+\dot{U}-c \dot{\omega}) \times \cos \left(\varphi_{1}+\varphi_{2}\right)\right]+l_{2}\left[-\left(\dot{\omega}-\ddot{\varphi}_{1}\right) \cos \varphi_{3}+\left(\omega-\dot{\varphi}_{1}\right)^{2} \sin \varphi_{3}\right)\right]\right)+ \\
& +l_{3} m_{4} d_{4}\left[-\left(\dot{\omega}-\ddot{\varphi}_{1}-\ddot{\varphi}_{3}-\ddot{\varphi}_{4}\right) \cos \varphi_{4}-\left(\omega-\dot{\varphi}_{1}-\dot{\varphi}_{3}-\dot{\varphi}_{4}\right)^{2} \sin \varphi_{4}\right]= \\
& =l_{3}\left[X_{41} \times \sin \left(\theta_{12}+\varphi_{4}\right)+Y_{41} \times \cos \left(\theta_{12}+\varphi_{4}\right)+M_{3}-M_{4} ;\right.
\end{aligned}
$$

\section{- для керованої осі другого причепа}

$$
\begin{aligned}
& \left(I_{4}+m_{4} d_{4}^{2}\right) \times\left(\ddot{\varphi}_{4}+\ddot{\varphi}_{3}+\dot{\omega}+\ddot{\varphi}_{1}\right)+m_{4} d_{4} \times\left(\left[\left(\dot{U}-V \omega+c \omega^{2}\right) \times\right.\right. \\
& \left.\times \sin \left(\varphi_{1}+\varphi_{3}+\varphi_{4}\right)+(V \omega+\dot{U}-c \dot{\omega}) \times \cos \left(\varphi_{1}+\varphi_{3}+\varphi_{4}\right)\right]-l_{3}\left[\left(\dot{\omega}-\ddot{\varphi}_{1}-\ddot{\varphi}_{3}\right) \cos \varphi_{4}-\right. \\
& \left.\left.\left.-\left(\omega-\dot{\varphi}_{1}-\dot{\varphi}_{3}\right)^{2} \sin \varphi_{4}\right)\right]\right)-l_{2}\left[\left(\dot{\omega}-\ddot{\varphi}_{1}\right) \cos \left(\varphi_{3}+\varphi_{4}\right)-\left(\omega-\dot{\varphi}_{1}\right)^{2} \sin \left(\varphi_{3}+\varphi_{4}\right)\right]= \\
& =\left(d_{4}+b_{4 \rho}\right)\left[X_{41} \times \sin \theta_{12}+Y_{41} \times \cos \theta_{12}+Y_{42}\right]-H_{4}\left(X_{41} \times \cos \theta_{12}+X_{42}-Y_{41} \times \sin \theta_{12}+M_{4} .\right.
\end{aligned}
$$

У системі рівнянь (1) прийняті такі позначення:

$\mathrm{m}_{\mathrm{i}}, \mathrm{I}_{\mathrm{i}}$ - маса і центральний момент інерції ланок метробуса щодо вертикальної осі;

$\vartheta_{\mathrm{i}}$ - курсові кути ланок метробуса;

$\varphi_{1}-$ кути складання кінематично незалежних ланок метробуса;

$v_{i}, u_{i}$ - поздовжня і бокова проекції швидкості центрів мас ланок метробуса;

$\omega_{\mathrm{i}}$ - кутова швидкість ланок метробуса щодо вертикальної осі;

$M_{\mathrm{ki}}=f\left(\varphi_{k}, \dot{\varphi}_{k}\right)$ - моменти опору повороту ланок метробуса;

$X_{\mathrm{ij}}, Y_{\mathrm{ij}}, Z_{\mathrm{ij}}$ - поздовжні, бокові і вертикальні реакції опорної поверхні на колеса осей метробуса;

$a$ - відстань від передньої осі до центра мас автобуса;

в - відстань від задньої осі до центра мас автобуса;

$c$ - відстань від центра мас автобуса до точки зчіпки з першим напівпричепом (причепом);

$b_{1}-$ відстань від центра мас першої причіпної ланки до її осі (за напівпричіпної схеми) і передньої осі (за причіпної схеми);

в 12 - відстань від центра мас першої причіпної ланки до її задньої осі (за причіпної схеми);

$c_{1}-$ відстань від центра мас першої причіпної ланки до точки зчіпки з автобусом;

$c_{2}$ - відстань від точки зчіпки автобуса 3 першою причіпною ланкою до його осі (за напівпричіпної семи) і до його задньої осі (за причіпної схеми);

в2 - відстань від центра мас другої причіпної ланки до його осі (за напівпричіпної схеми) і передньої осі (за причіпної схеми);

в22- відстань від центра мас другої причіпної ланки до іії задньої осі (за причіпної схеми);

$d_{l}-$ відстань від центра мас першої причіпної ланки до точки зчіпки з автобусом;

$d_{2}$ - відстань від центра мас першої причіпної ланки до точки зчіпки з другою;

$d_{3}-$ відстань від центра мас другої причіпної ланки до центра мас першої причіпної ланки;

$d_{4}$ - відстань від центра мас другої причіпної ланки до точки зчіпки з автобусом;

Для метробуса, виконаного за напівпричіпною схемою, слід прийняти $\mathrm{m}_{1}=\mathrm{m}_{3}=0, \mathrm{I}_{2}=\mathrm{I}_{4}=0$, $\mathrm{v}_{1}=\mathrm{v}_{3}=0, \mathrm{u}_{1}=\mathrm{u}_{3}=0, \mathrm{X}_{31}=\mathrm{X}_{41}=0, \mathrm{Y}_{31}=\mathrm{Y}_{41}=0, \theta_{11}=\theta_{12}=0$.

Отримана система рівнянь дозволяє досліджувати поведінку триланкового автопоїзда як у стаціонарних, так і нестаціонарних рухах, а також визначати критичну швидкість $v_{\kappa p}$ автопоїзда, яка має два підходи до своєї кількісної оцінки [7]: перший зв'язаний с дослідженням характеристичних рівнянь (1-й метод Ляпунова) чи функції Ляпунова (2-й метод Ляпунова), другий - 3 виходом параметрів руху за припустиму область. Критерій $v_{\kappa p}$ зв'язує конструктивні й експлуатаційні 
параметри автопоїзда та його швидкість і дозволяє знайти іiі верхню межу, перевищення якої приводить до втрати стійкості руху.

Аналітичні вирази для змінних $U\left(\theta_{1}\right), \omega\left(\theta_{1}\right), \varphi_{i}\left(\theta_{1}\right)$, що відповідають усталеним рухам $\left(\dot{U}=0, \dot{\omega}=0, \dot{\varphi}_{i}=0, \ddot{\varphi}_{i}=0 \quad(i=1,4)\right)$, можна отримати із системи рівнянь (1) на коловій траєкторії досить великого радіуса за умови, що $V=$ const [7]:

$$
\left\{\begin{array}{l}
\left(m+m_{1}+m_{2}+m_{3}+m_{4}\right) \omega V=Y_{1}+Y_{2}+\sum_{j=1}^{2} Y_{2 j}+\sum_{\rho=1}^{2} Y_{4 \rho} ; \\
-c\left(m_{1}+m_{2}+m_{3}+m_{4}\right) \omega V=a Y_{1}-b_{1} Y_{2}-c\left(\sum_{j=1}^{3} Y_{2 j}+\sum_{\rho=1}^{3} Y_{4 \rho}\right)+M_{1} \\
{\left[m_{1} d_{1}+m_{2} l_{1}+\left(m_{3}+m_{4}\right) l_{2}\right]=l_{1} \sum_{i=1}^{2} Y_{2 j}+l_{2} \sum_{\rho=1}^{3} Y_{4 \rho}+M_{1}-M_{2} ;} \\
m_{2} d_{2} \omega V=\sum_{j=1}^{3} Y_{2 j}\left(d_{2}+b_{2 j}\right)+M_{3} ; \\
\left(m_{3} d_{3}+m_{4} l_{3}\right) \omega V=l_{3} \sum_{\rho=1}^{3} Y_{4 \rho}+M_{3}-M_{4} \\
m_{4} d_{4} \omega V=\sum_{\rho=1}^{3} Y_{4 \rho}\left(d_{4}+b_{4 \rho}\right)+M_{3}+M_{4}
\end{array}\right.
$$

У системі рівнянь (2) $j, \rho$ - відповідно кількість осей першого і другого причепа.

Розв’язати систему рівнянь (2) у загальному вигляді і проаналізувати залежності величин бічної і кутової швидкості автобуса $U$ і $\omega$ та кутів складання метробуса $\varphi_{1}$ від конструктивних параметрів автопоїзда неможливо із-за складності розкриття визначника шостого порядку i громіздкості самих виразів. Тому для обчислення визначників системи (2) необхідно залучити числові методи, наприклад, програмне забезпечення Mapple. Тоді змінні, що отримані за допомогою програмного забезпечення Мapple, дозволять визначити вплив різноманітних конструктивних i експлуатаційних факторів на показники стійкості руху автопоїзда.

За лінійності сил бічного відведення $Y_{i j}$ у функції кута відведення $\delta_{i j}$ отримаємо [6]:

$$
\begin{aligned}
& Y_{i j}=k_{i j} \delta_{i j} ; \quad \delta_{1}=\theta_{1}-\frac{U+a \omega}{V} ; \\
& \delta_{2 j}=-\theta_{11}-\frac{U}{V}+\frac{\omega}{V}\left(c+l_{1}+d_{2}+b_{2 j}\right)-\varphi_{1}-\varphi_{2} \\
& \delta_{4 \rho}=-\theta_{12}-\frac{U}{V}+\frac{\omega}{V}\left(c+l_{2}+l+d_{4}+b_{4 \rho}\right)-\varphi_{1}-\varphi_{3}-\varphi_{4}
\end{aligned}
$$

де $\theta_{1}, \theta_{2 j}, \theta_{4 \rho}-$ кути повороту керуючого колісного модуля, керованої осі першого і другого причепа.

3 урахуванням виразів, що визначають бічні сили і кути відведення осей автопоїзда, розв’ язками системи рівнянь (3) будуть значення змінних, що відповідають стаціонарним режимам, а саме:

$$
U=\frac{\Delta_{U}}{\Delta} ; \quad \omega=\frac{\Delta_{\omega}}{\Delta} ; \quad \varphi_{1}=\frac{\Delta_{\varphi 1}}{\Delta} ; \quad \varphi_{2}=\frac{\Delta_{\varphi 2}}{\Delta} ; \quad \varphi_{3}=\frac{\Delta_{\varphi 3}}{\Delta} ; \quad \varphi_{4}=\frac{\Delta_{\varphi 4}}{\Delta},
$$


де $\Delta$ - головний визначник системи, $\Delta_{\mathrm{U}}, \Delta_{\omega}, \Delta_{\varphi 1}, \Delta_{\varphi 2}, \Delta_{\varphi 3}, \Delta_{\varphi 4}$ - визначники системи для знаходження відповідних змінних.

Корені характеристичних рівнянь можна визначити чисельними методами. Зауважимо при цьому, що опис руху автопоїзда, що реально є нелінійним об'єктом, лінійними рівняннями $є$ заміною однієї задачі іншою, з яким перша може не мати нічого спільного (через неврахування нелінійності відведення і членів вище першого порядку рівнянь руху) [6].

Звідси виникає наступна задача: установити необхідні і достатні умови стійкості за першим наближенням. Відповідно до теореми Ляпунова про стійкість сталого руху за першим наближенням [6], якщо всі корені характеристичного рівняння системи першого наближення рівнянь збуреного руху мають від’ємні дійсні частини, то незбурений рух є стійким і притому асимптотично стійким, якими б не були члени вищих порядків у диференціальних рівняннях збуреного руху.

Умови, за яких усі корені мають від’ємні дійсні частини, визначаються критерієм ЛьенараШипара [6]: для того щоб характеристичне рівняння мало всі корені з від’ємними дійсними частинами, необхідно і достатньо, щоб:

1) усі коефіцієнти характеристичного рівняння були позитивні;

2) були позитивними головні діагональні мінори матриці Гурвіца, що складені для даного характеристичного рівняння. Ці умови виконуються у разі додатності знаменника $\omega$ (3), тобто додатності знаменника головного визначника системи, що має вигляд

$$
V<V_{k p}=\beta /(-\alpha)
$$

Якщо представити головний визначник у вигляді суми двох визначників

$$
\left\|a_{i j}\right\|_{1}^{6}=V^{2} \times\left\|\beta_{i j}\right\|_{1}^{6}+\left\|\alpha_{i j}\right\|_{1}^{6},
$$

де $\beta_{i j}=\alpha_{i j}=a_{i j}(i=\overline{1}, \overline{6} ; j=1,3,4,5,6)$.

$$
\begin{aligned}
& \text { Якщо } \mathrm{j}=2 \text {, то } \beta_{12}=m+m_{1}+m_{2}+m_{3}+m_{4} ; \\
& \beta_{22}=-c\left(m_{1}+m_{2}+m_{3}+m_{4}\right) ; \beta_{42}=m_{2} d_{2} ; \beta_{52}=m_{3} d_{4}+m_{4} l_{3} ; \beta_{62}=m_{4} d_{4 ;} \\
& \alpha_{12}=k_{1} a-\sum_{i=1}^{2} k_{1 i} b_{1 i}-\sum_{j=1}^{3} k_{2 j}\left(c+l_{1}+d_{2}+b_{2 j}\right)-\sum_{\rho=1}^{3} k_{4 \rho}\left(c+l_{2}+l_{3}+d_{4}+b_{4 \rho}\right) ; \\
& \alpha_{22}=k_{1} a^{2}+\sum_{i=1}^{2} k_{1 i} b_{1 i}^{2}+c \sum_{j=1}^{3} k_{2 j}\left(c+l_{1}+d_{2}+b_{2 j}\right)+c \sum_{\rho=1}^{3} k_{4 \rho}\left(c+l_{2}+l_{3}+d_{4}+b_{4 \rho}\right) ; \\
& \alpha_{32}=l_{1} \sum_{j=1}^{3} k_{2 j}\left(c+l_{1}+d_{2}+b_{2 j}\right)+l_{2} \sum_{\rho=1}^{3} k_{4 \rho}\left(c+l_{2}+l_{3}+d_{4}+b_{4 \rho}\right) ; \\
& \alpha_{42}=\sum_{j=1}^{3} k_{2 j}\left(d_{2}+b_{2 j}\right)\left(c+l_{1}+d_{2}+b_{2 j}\right) ; \alpha_{52}=l_{3} \sum_{\rho=1}^{3} k_{4 \rho}\left(c+l_{2}+l_{3}+d_{4}+b_{4 \rho}\right) ; \\
& \alpha_{62}=-\sum_{\rho=1}^{3} k_{4 \rho}\left(d_{4}+b_{4 \rho}\right)\left(c+l_{2}+l_{3}+d_{4}+b_{4 \rho}\right),
\end{aligned}
$$

то $\alpha$ і $\beta$ у (6) будуть визначатися як

$$
\beta=\left\|\beta_{i j}\right\|_{1}^{6} ; \quad \alpha=\left\|\alpha_{i j}\right\|_{1}^{6} .
$$

Розв'язок рівняння (7) здійснено за допомогою програмного забезпечення Mapple. Розрахунки виконані для триланкових метробусів, виконаних за причіпною і напівпричіпною схемою за таких вихідних даних [він]:

$a=3,58 ; b=2,32 ; b b=0 ; c=4,71 ; c_{o l}=2,5 ; L_{o}=12 ; B=1.86 ; b_{1}=0,5$ (за напівпричіпної схеми) і $\theta_{1}=2,9$ (за 
причіпної схеми); $в_{12}=3,1 ; c_{1}=3,9 ; c_{2}=0,5$ (за напівпричіпної семи) і $c_{2}=2,9$ (за причіпної схеми); $L_{1}$ $=6,2 ; b_{2}=0,5$ (за напівпричіпної схеми) і $в_{2}=2,9$ (за причіпної схеми); $b_{22}=3,1 ; d_{2}=3,9$;

$k f$ - коефіцієнт опору кочення коліс метробуса; $L_{I}=L_{2}=6,9 ; \quad q_{1}=130000 ; q_{2}=220000 ; q_{3}=180000$; $q_{31}=110000 ; q_{32}=130000 ; q_{41}=110000 ; q_{42}=130000 ; \chi_{1}=1780 ; \chi_{2}=1500 ; \chi_{3}=1500 ; h_{1 \mathrm{~T}}=30 ; h_{2 \mathrm{~T}}=30 ; h_{3 \mathrm{~T}}=30$; $\varphi_{1}=0,8 ; m_{1}=400 ; J_{1}=16,9 ; m_{2}=9600 ; \quad J_{2}=27300 ; m_{3}=400 ; J_{3}=16,9 ; m_{4}=9600 ; J_{4}=27300 ; f=0 ; V=0$ $\theta=0,35 ; \theta_{2}=\theta_{3}=f\left(\varphi_{i}\right), \varphi_{1}=\varphi_{2}=\varphi_{3}=\varphi_{4}=0,8 ; V:=0 ; X 1=X 2=X 3=X 31=X 32=X 4=X 41=X 42=0$.

Для обраних для розрахунку метробусів критична швидкість руху склала:

для причіпного - 26,21 м/с;

для напівпричіпного $-31,19 \mathrm{~m} / \mathrm{c}$.

Зважаючи на те, що рух метробусів здійснються по окремо виділеним смугам зі швидкістю $25 \ldots 30 \mathrm{~m} / \mathrm{c}$, у подальшому було проааналізовано конструктивних параметрів автобуса і причепів на величину критичної швидкості руху.

На рис. 4-5 наведені результати розрахунків критичної швидкості руху причіпного автопоїзда (автопоїзд №1) і напівпричіпного (автопоїзд №2) в залежності від їх конструктивних параметрів.

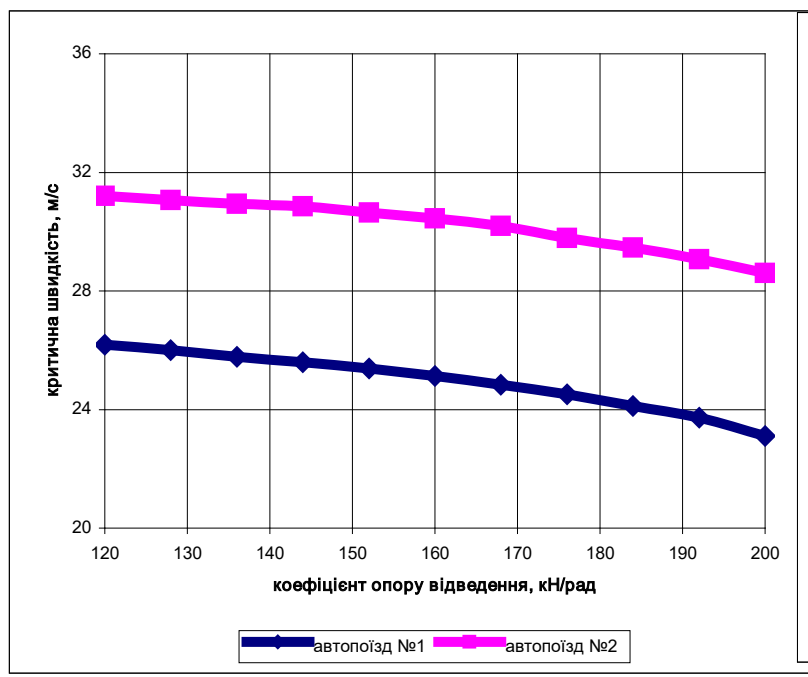

a)

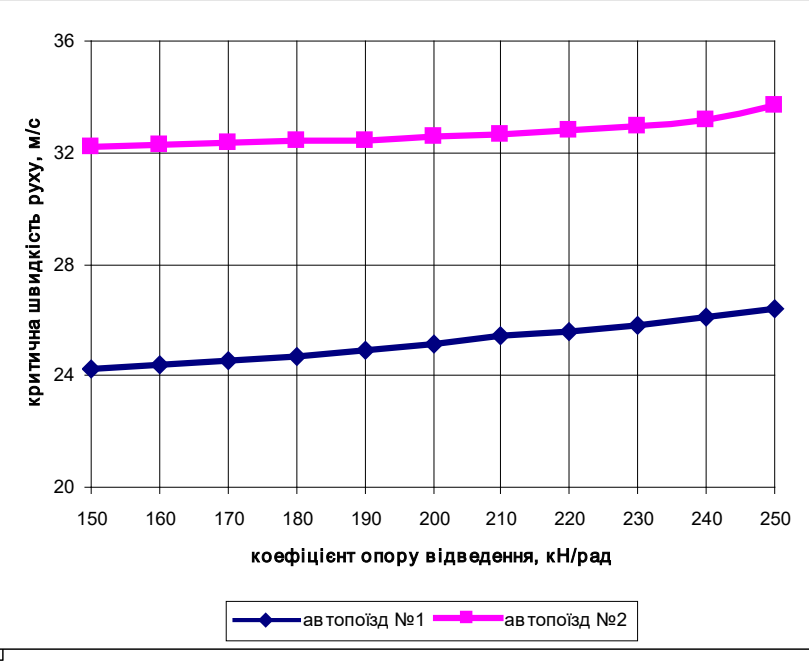

б)

Рис. 4. Залежність критичної швидкості руху метробуса від коефіцієнта опору відведення коліс перших осей ланок (a) і других осей ланок (б) причіпних секцій

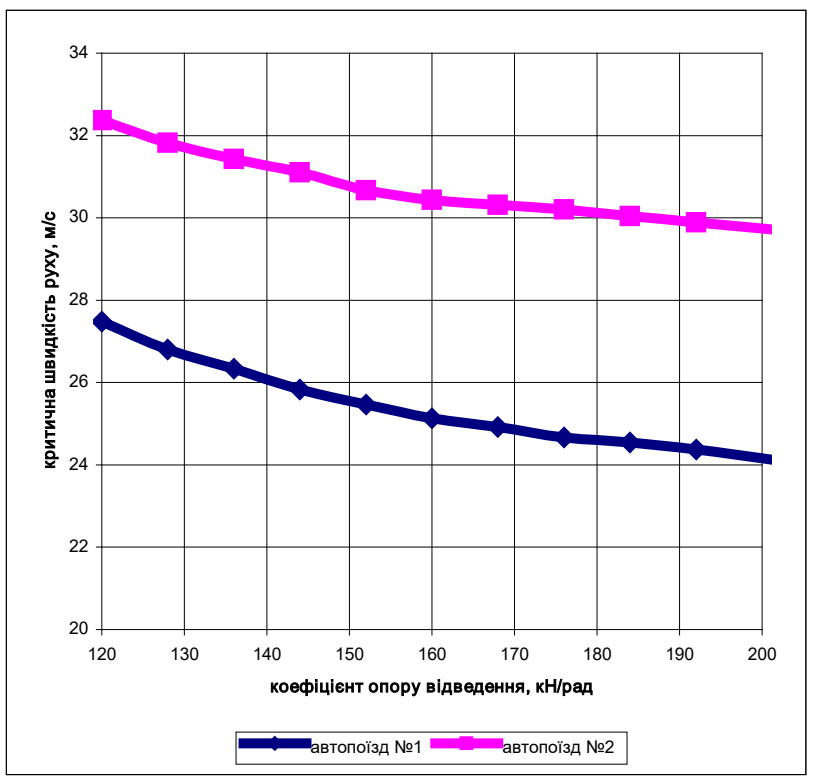

a)

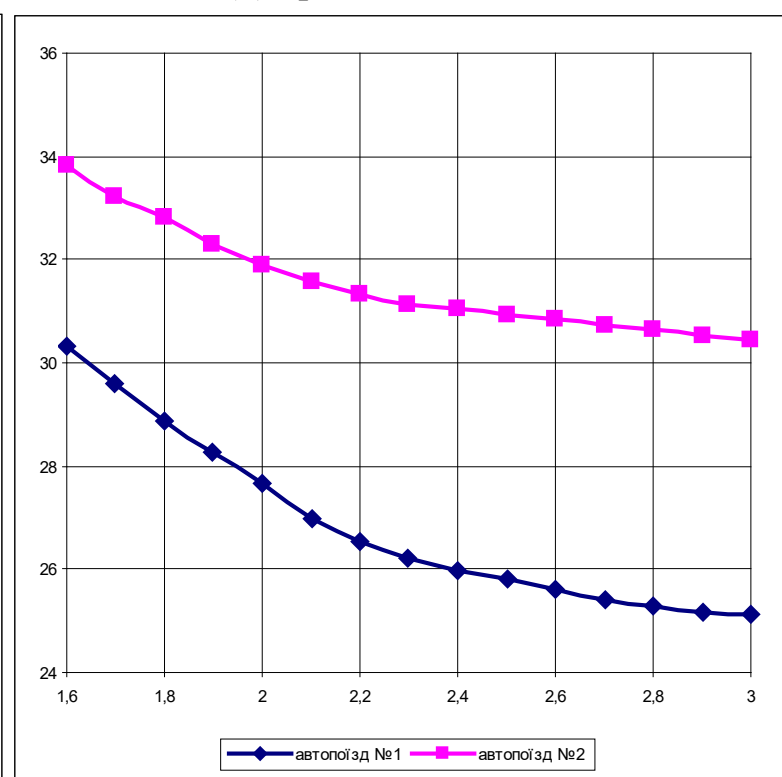

б)

Рисунок 5. - Залежність критичної швидкості руху метробуса від коефіцієнта опору відведення керованих коліс автобуса (а) і від відстані між центром мас тягача і точкою його зчіпки 3 першою причіпною ланкою 
Аналіз наведених залежностей показує, що на підвищення поперечної горизонтальної стійкості метробуса позитивно позначається зменшення тиску повітря в шинах передньої осі і збільшення в шинах задньої осі першого причепа (напівпричепа), зсув центра мас причіпних ланок до передньої осі, збільшення коефіціснтів опору бічному відведенню шин коліс другої осі причепа (напівпричепа), збільшення маси автобуса і першого причепа тощо. Вплив інших параметрів або незначний, або зовсім відсутній.

\section{ОБГОВОРЕННЯ РЕЗУЛЬТАТІВ ДОСЛІДЖЕНЬ}

Виконано порівняння триланкових метробусів різних компонувальних схем за показниками стійкості руху. Показано, що за величиною критичної швидкості руху перевагу слід віддати триланковому метробусу, виконаному за напівпрчіпною схемою. Визначені шляхи підвищення критичної швидкості руху метробуса, виконаного за причіпною схемою. Проте судити взагалі про стійкість руху лише в одному режимі, а саме в прямолінійному русі, недостатньо. Необхідно розглянути стійкість метробуса у перехідних режимах руху при виконанні ним різних маневрів. Це може стати предметом подальших досліджень

\section{ПЕРЕЛІК ДЖЕРЕЛ ПОСИЛАННЯ}

1. https://autotheme.info/news/103250-pokazan-24-metrovyj-polskij-trollejbus.html

2. https://griphon.livejournal. com $/ 222403$.

3. Трехзвенные автопоезда /Я.Е.Фаробин, А.М.Якобашвили, А.М.Иванов и др. Под общ. ред. Я.Е.Фаробина - Машиностроение, 1993. - 224 с.: ил.

4. Sakhno V. Lorry convoy stability taking into account the skew of semitrailer axes /V.Sakhno, V.Poliakov, O.Timkov, O.Kravchenko//Transport Problems. Volume 11. Issue 3. Wydawnictwo politechniki SlaskiejGliwice, 2016, p. 69-76.

5.Сахно В.П. Маневреність метробусів /В.П.Сахно, В.В.Біліченко, В.М.Поляков, О.Є.Омельницький //Вісник Машинобудування та транспорту. Вінниця, 2018 - № 2. - С. 97-105.

6.Volodymyr SAKHNO, Victor POLIAKOV, Igor MUROVANYI, Vadim SELEZNIOV, Yuriy VOVK. Analysis of transverse stability parameters of hybrid buses with active trailers//Scientific Journal of Silesian University of Technology. Series Transport. 2018, 101, 185-201.

7. Volodimir Sakhno, Juraj Gerlici, Victor Poliakov, Alexandr Kravchenko, Oleg Omelnitsky, Tomas Lask. Road train motion stability in BRT system //XXIII Polish-Slovak Scientific Conference Machine Modelling and Simulation. MMS 2018.- Book of abstracts, September 4-7, 2018, Rydzyna Poland, p.49.

Road train motion stability in BRT system// MATEC Web of Conferences 254, 03007 (2019) https://doi.org/10.1051/matecconf/201925403007. MMS 2018

8. Sakhno V. Determination of movement stability of especiality large class hybrid bus with active trailer/V.Sakhno, V. Poljakov, I.Myrovany, V.Seleznov//INMATEN - Agricultural engineering. - Vol.49/ No2/2016. - P.107-118.

\section{REFERENCES}

1. https://autotheme.info/news/103250-pokazan-24-metrovyj-polskij-trollejbus.html

2. https://griphon.livejournal. com $/ 222403$.

3. Farobin Ya. E., Yakobashvili A. M., Ivanov A.M. (1993). Three-link road trains. Mechanical Engineering, $224 \mathrm{p}$.

4. Sakhno V., Poliakov V., Timkov O., Kravchenko O. (2016) Lorry convoy stability taking into account the skew of semitrailer axes. Transport Problems, 11 (3), 69-76.

5. Sakhno V. P. (2017). Maneuverability of metrobusysv. Bulletin of mechanical engineering and transport: scientific, 2 (6), 131-140.

6. . Sakhno V., Poliakov V., Murovanyi I., Selezniov V., Vovk J. (2018). Analysis of transverse stability parameters of hybrid buses with active trailers, 101, 185-201.

7. Sakhno V., Gerlici J., PoliakovV., Kravchenko A., Omelnitsky O., Lask T. (2018). Road train motion stability in BRT system. XXIII Polish-Slovak Scientific Conference Machine Modelling and Simulation, 49.

8. Sakhno V., Murovany I., Selezniov V. (2016). Determination of movement stability of especiality large class hybrid bus with active trailer. Agricultural engineering, 49 (2), 107-118. 


\section{V.Sakhno, I. Myrovany, V.Poljakov, E.Misko To comparative assessment of three-unit lorry passenger trains.}

In the modern automobile industry when creating multi-trailers auto-trains, including passenger trains, the question of the choice of trailers is urgent and it is actively discussed in the literature. There are two main schemes of multi-trailers auto-trains - trailed and semi-trailed. In the trailed diagram, each trailer rests on its axes, in the semi-trailed one - both on its axes and on the axis of the previous trailer (articulated buses and trolleybuses). The theoretical foundations of the analysis are based on mathematical models of straightforward and controllable car and auto-train movements, which are designed for cars, two- and threetrailed auto-trains.

However, their application to three-trailed metrobuses is problematic due to the different layout of the auto-trains and metrobuses, different loads on individual trailers, different control systems, etc. Hence the problem of predicting the agility and stability of the movement of three-trailed metrobuses during their movement both in the general traffic flow and on specially allocated lanes, which determined the purpose and objectives of the study. The purpose of the work is to improve the stability of the three-trailed metrobuses by choosing a rational layout scheme and design parameters of its trailer.

According to the purpose, the tasks of the study were defined, for which the metrobus was presented in the form of three modules - a bus and two trailers. For such a metrobus, differential equations of planeparallel motion were recorded, the solution of which allowed us to determine the critical speed of movement and to carry out a comparative analysis of different layout schemes of metrobuses for stability of movement.

Due to the fact that the traffic of metrobuses is carried out on separate lanes with a speed of $25 \ldots 30$ $\mathrm{m} / \mathrm{s}$, the influence of the design parameters of the bus and trailers on the value of the critical speed of movement is analyzed. It is established that the increase of the transverse horizontal stability of the metrobus is positively affected by the reduction of the air pressure in the front axe tires and the increase in the rear axe tires of the first trailer (semi-trailer), the displacement of the center of mass of the trailers to the front axe, the increase of the coefficients of lateral tire deflection of the wheels (semi-trailer), increasing the mass of the bus and the first trailer, etc. The influence of other parameters is either negligible or nonexistent. However, judging in general the stability of movement only at a critical speed movement is not enough. Consideration should be given to the stability of the metrobus in transient driving modes when performing various maneuvers. This may be the subject of further research.

Key words: metro, bus, trailer, semi-trailer, equation of motion, stability, speed, assembly angles, controls.

САХНО Володимир Прохорович, доктор технічних наук, професор, завідувач кафедри автомобілів, Національний транспортний університет e-mail: svp 40@ukr.net. https://orcid.org/00000002-5144-7131

МУРОВАНИЙ Ігор Сергійович, кандидат технічних наук, доцент, завідувач кафедри автомобілів i транспортних технологій, Луцький національний технічний університет е-mail: igor_lntu@ukr.net. https://orcid.org/0000-0002-9749-980X

ПОЛЯКОВ Віктор Михайлович, кандидат технічних наук, доцент, професор кафедри автомобілів, Національний транспортний університет e-mail: poljakov_2006@ukr.net. https://orcid.org/0000-0001-7042-3066

МІСБКО Євген Михайлович, старший викладач кафедри машинобудування, Одеської державної академії будівництва та архітектури, e-mail: dreadfull87@,gmail.com

Volodymyr SAKHNO, Doctor of Science in Engineering, Professor, Head of Automobiles

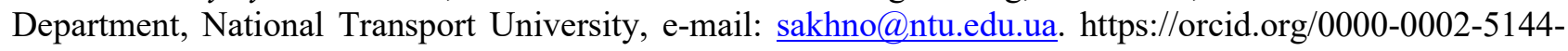
7131

Igor MUROVANYI, PhD. in Engineering, Assoc. Professor, Head of Motor Cars and Transport Technologies Department, Lutsk National Technical University, e-mail: igor_ntu@ukr.net https://orcid.org/0000-0002-9749-980X

Victor POLYAKOV, Ph.D., associate professor, professor of «Automobiles», National Transport University, e-mail: poljakov_2006@ukr.net. https://orcid.org/0000-0001-7042-3066

Yevgen MISKO, lecturer of Department of Mechanical, Engineering Odessa State Academy of Civil Engineering and Architecture, e-mail: dreadful187@gmail.com 